\title{
Start of Micrometer-Sized Oil Droplet Motion through Generation of
}

\section{Surfactants}

Yui Kasuo ${ }^{1}$, Hiroyuki Kitahata ${ }^{2}$, Yuki Koyano ${ }^{3}$, Masahiro Takinoue ${ }^{4}$, Kouichi Asakura ${ }^{1}$ and Taisuke Banno ${ }^{1, *}$

${ }^{1}$ Department of Applied Chemistry, Faculty of Science and Technology, Keio University, 3-14-1 Hiyoshi, Kohokuku, Yokohama 223-8522, Japan

${ }^{2}$ Department of Physics, Graduate School of Science, Chiba University, 1-33 Yayoi-cho, Inage-ku, Chiba 263-8522, Japan

${ }^{3}$ Department of Physics, Tohoku University, 6-3 Aramaki-azaaoba, Aoba-ku, Miyagi 980-8578, Japan

${ }^{4}$ Department of Computer Science, Tokyo Institute of Technology, 4259 Nagatsuta-cho, Midori-ku, Yokohama 2268502, Japan

\section{Supporting Information Index}

Synthetic procedures

Figures

Table

Description of video clips
... p. S2

...p. S5

...p. S9

... p. S10 


\section{Synthetic procedures}

\section{Synthesis of 4-azidobenzoyloxyethylene- $N, N, N$-trimethylammonium bromide (AZ)}

Synthesis of 4-azidobenzoyloxyethylene-dimethylamine

To a mixture of 4-azidobenzoic acid (0.974 g, $6.0 \mathrm{mmol})$, 2-dimethylaminoethanol (642 mg, $7.2 \mathrm{mmol})$, and $N, N$-dimethyl-4-aminopyridine $(0.165 \mathrm{~g}, 1.4 \mathrm{mmol})$ in $8 \mathrm{~mL}$ of THF, $N, N^{\prime}$-dicyclohexylcarbodiimide $(1.52 \mathrm{~g}$, $7.4 \mathrm{mmol}$ ) in $4 \mathrm{~mL}$ of THF was added dropwise at $0^{\circ} \mathrm{C}$. The resulting solution was stirred under argon at room temperature for $17 \mathrm{~h}$. After the reaction, the solvent was removed by evaporation under reduced pressure. The obtained crude product dissolved in $n$-hexane and was filtered using a membrane filter, and dried over $\mathrm{MgSO}_{4}$. Purification was carried out by silica gel column chromatography with $n$-hexane/EtOAc $[1 / 1(\mathrm{v} / \mathrm{v})]$ and $\mathrm{CHCl}_{3} / \mathrm{MeOH}[4 / 1(\mathrm{v} / \mathrm{v})]$ to obtain 4-azidobenzoyloxyethylene-dimethylamine as a yellow syrup at a yield of $51 \%(0.710 \mathrm{~g}, 3.0 \mathrm{mmol})$.

${ }^{1} \mathrm{H} \mathrm{NMR}\left(500 \mathrm{MHz}, \mathrm{CDCl}_{3}\right) \delta 8.10-7.99(\mathrm{~m}, 2 \mathrm{H}), 7.10-7.01(\mathrm{~m}, 2 \mathrm{H}), 4.41(\mathrm{t}, J=5.7 \mathrm{~Hz}, 2 \mathrm{H}), 2.70(\mathrm{t}, J=5.9$ $\mathrm{Hz}, 2 \mathrm{H}), 2.33(\mathrm{~s}, 6 \mathrm{H})$. HR-ESI-MS $(\mathrm{m} / \mathrm{z})$ : calcd for $\mathrm{C}_{11} \mathrm{H}_{15} \mathrm{~N}_{4} \mathrm{O}_{2} 235.1195[\mathrm{M}+\mathrm{H}]^{+}$; found $235.1206[\mathrm{M}+\mathrm{H}]^{+}$. Synthesis of 4-azidobenzoyloxyethylene-N,N,N-trimethylammonium bromide (AZ)

To 4-azidobenzoyloxyethylene-dimethylamine $(0.488 \mathrm{~g}, 2.08 \mathrm{mmol})$ in THF (3.95 mL), bromomethane solution of $2 \mathrm{~mol} / \mathrm{L}$ THF $(1.25 \mathrm{~mL}, 2.50 \mathrm{mmol})$ was added dropwise at $0^{\circ} \mathrm{C}$. The resulting solution was stirred under argon at room temperature $\left(24-26^{\circ} \mathrm{C}\right)$ for $7 \mathrm{~h}$. After the reaction, the solvent was evaporated to obtain 
the crude product. Purification was carried out by reprecipitation using methanol $(3.5 \mathrm{~mL})$ and ethyl acetate $(22.0 \mathrm{~mL})$ to obtain $\mathbf{A Z}$ as a pale yellow solid at a yield of $76 \%(0.518 \mathrm{~g}, 1.57 \mathrm{mmol})$.

${ }^{1} \mathrm{H}$ NMR (500 MHz, DMSO- $\left.d_{6}\right) \delta 8.02(\mathrm{dt}, J=9.0,2.3 \mathrm{~Hz}, 2 \mathrm{H}), 7.28(\mathrm{dd}, J=6.8,1.9 \mathrm{~Hz}, 2 \mathrm{H}), 4.70(\mathrm{~d}, J=$ $2.5 \mathrm{~Hz}, 2 \mathrm{H}), 3.83-3.78(\mathrm{~m}, 2 \mathrm{H}), 3.20(\mathrm{~d}, J=6.9 \mathrm{~Hz}, 9 \mathrm{H})$. HR-ESI-MS $(\mathrm{m} / \mathrm{z})$ : calcd for $\mathrm{C}_{12} \mathrm{H}_{17} \mathrm{~N}_{4} \mathrm{O}_{2} 249.1343$ $[\mathrm{M}-\mathrm{Br}]^{+}$; found $249.1323[\mathrm{M}-\mathrm{Br}]^{+}$.

Synthesis of 4-(octyl triazole)benzoic acid

To a mixture of 4-azidobenzoic acid (3.38 g, $21 \mathrm{mmol})$ and 1-decyne (3.32 g, $24 \mathrm{mmol})$ in THF (80 mL), an aqueous solution $(10 \mathrm{~mL})$ of $\mathrm{CuSO}_{4} \cdot 5 \mathrm{H}_{2} \mathrm{O}(99.8 \mathrm{mg}, 0.40 \mathrm{mmol})$ and an aqueous solution $(10 \mathrm{~mL})$ of $\mathrm{L}_{\text {-sodium }}$ ascorbate $(792 \mathrm{mg}, 4.0 \mathrm{mmol}$ ) were added. The reaction mixture was then stirred for $24 \mathrm{~h}$ at room temperature $\left(24-26^{\circ} \mathrm{C}\right)$. After removal of the volatile components in vacuo, the residue was extracted with ethyl acetate $(100 \mathrm{~mL})$ and washed four times with brine $(200 \mathrm{~mL})$, then dried using $\mathrm{Na}_{2} \mathrm{SO}_{4}$. The obtained filtrate was evaporated to give the crude product, which was purified by recrystallisation in THF (150 mL) to give 4-(octyl triazole)benzoic acid as a white solid $(4.29 \mathrm{~g}, 69 \%)$.

${ }^{1} \mathrm{H}$ NMR (500 MHz, DMSO- $\left.d_{6}\right) \delta 8.69(\mathrm{~s}, 1 \mathrm{H}), 8.12(\mathrm{dd}, J=7.0,1.9 \mathrm{~Hz}, 2 \mathrm{H}), 8.03(\mathrm{dd}, J=6.8,1.9 \mathrm{~Hz}, 2 \mathrm{H})$, $2.70(\mathrm{t}, J=7.6 \mathrm{~Hz}, 2 \mathrm{H}), 1.72-1.61(\mathrm{~m}, 2 \mathrm{H}), 1.38-1.19(\mathrm{~m}, 10 \mathrm{H}), 0.85(\mathrm{t}, J=6.9 \mathrm{~Hz}, 3 \mathrm{H})$. HR-ESI-MS $(\mathrm{m} / z)$ : calcd for $\mathrm{C}_{17} \mathrm{H}_{24} \mathrm{~N}_{3} \mathrm{O}_{2} 302.1869[\mathrm{M}+\mathrm{H}]^{+}$; found $302.1864[\mathrm{M}+\mathrm{H}]^{+}$. 


\section{Synthesis of 4-(octyltriazole)benzoyloxyethelene- $N, N, N$-trimethylammonium bromide (TA)}

To a mixture of 4-(octyltriazole)benzoic acid (1.82 g, $6.2 \mathrm{mmol})$, 4-dimethylaminopyridine (149 $\mathrm{mg}, 1.2$ mmol), and 2-dimethylaminoethanol (642 mg, $7.2 \mathrm{mmol})$ in THF $(60 \mathrm{~mL})$, a solution of $N, N^{\prime}-$ dicyclohexylcarbodiimide $(1.49 \mathrm{~g}, 7.2 \mathrm{mmol})$ in THF $(10 \mathrm{~mL})$ was added. The reaction mixture was then stirred for $14 \mathrm{~h}$ at room temperature $\left(24-26^{\circ} \mathrm{C}\right)$ and filtered to remove the precipitate. Following evaporation of the filtrate, the residue was purified by silica gel column chromatography [chloroform/methanol, 10:1 (v/v)] to provide the crude 4-(octyl triazole)benzoyloxyethylene- $N, N$-dimethylamine as a pale yellow solid ( $0.99 \mathrm{~g})$.

The molecular structure of 4-(octyltriazole)benzoyloxyethylene- $N, N$-dimethylamine was confirmed by ${ }^{1} \mathrm{H}$ NMR and ESI-MS analyses.

To a solution of 4-(octyltriazole)benzoyloxyethylene- $N, N$-dimethylamine (containing other trace compounds) $(0.99 \mathrm{~g})$ in THF $(15 \mathrm{~mL}), 2 \mathrm{~mol} / \mathrm{L}$ bromomethane in THF $(1.6 \mathrm{~mL})$ was added dropwise at $0^{\circ} \mathrm{C}$. The reaction mixture was then stirred for $15 \mathrm{~min}$ at $0^{\circ} \mathrm{C}$ and subsequently for $23 \mathrm{~h}$ at room temperature (24$\left.26^{\circ} \mathrm{C}\right)$. Following evaporation of the solvent, the residue was purified by recrystallisation in chloroform $(3$ $\mathrm{mL})$ to obtain TA as a white solid (1.01 $\mathrm{g}, 36 \%$ yield over the two-step reaction).

${ }^{1} \mathrm{H} \mathrm{NMR}\left(500 \mathrm{MHz}, \mathrm{CDCl}_{3}\right) \delta 8.20(\mathrm{~d}, J=8.9 \mathrm{~Hz}, 2 \mathrm{H}), 7.87(\mathrm{~d}, J=8.7 \mathrm{~Hz}, 2 \mathrm{H}), 7.82(\mathrm{~s}, 1 \mathrm{H}), 4.92-4.86(2 \mathrm{H})$, $4.42(\mathrm{t}, J=4.6 \mathrm{~Hz}, 2 \mathrm{H}), 3.64(\mathrm{~s}, 9 \mathrm{H}), 2.79(\mathrm{t}, J=7.7 \mathrm{~Hz}, 2 \mathrm{H}), 1.78-1.68(\mathrm{~m}, 2 \mathrm{H}), 1.44-1.24(\mathrm{~m}, 10 \mathrm{H}), 0.88$ (t, $J=6.8 \mathrm{~Hz}, 3 \mathrm{H})$. HR-ESI-MS $(m / z)$ : calcd for $\mathrm{C}_{22} \mathrm{H}_{35} \mathrm{~N}_{4} \mathrm{O}_{2} 387.2760[\mathrm{M}-\mathrm{Br}]^{+}$; found $387.2726[\mathrm{M}-\mathrm{Br}]^{+}$. 


\section{Figures}

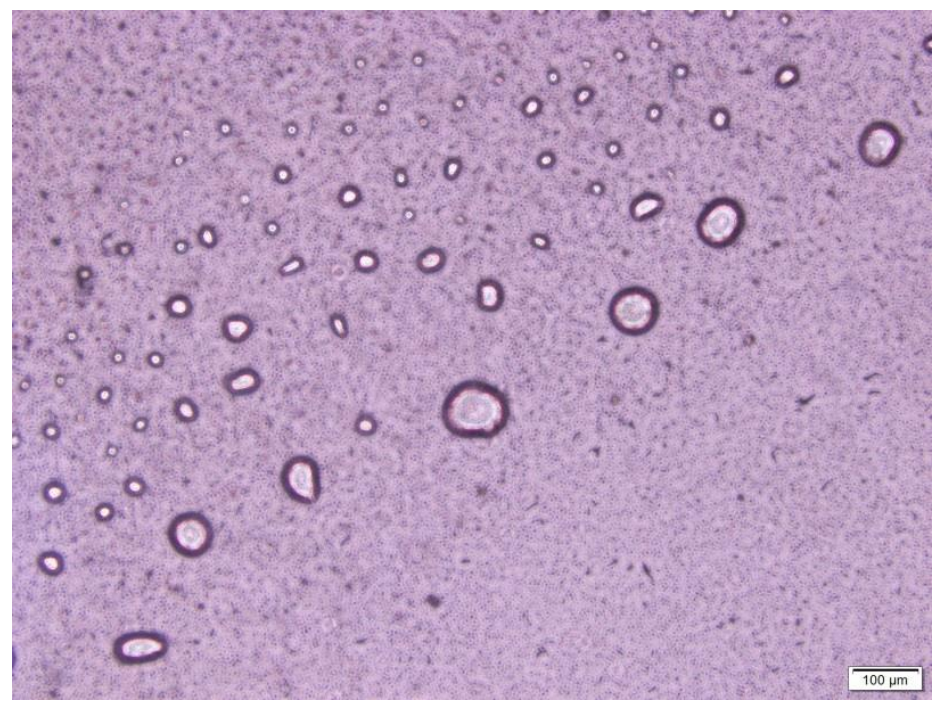

Figure S1. Typical microphotograph of oil droplets in the dispersion without 1-decyne 60 min after the start of observations. The self-propelled motion of droplets was not observed and their morphology simply remained. 




Figure S2. Phase-contrast micrograph of self-propelled motion of oil droplets with the formation of aggregates

from droplet surface as indicated by black arrows. White arrows indicate the direction of self-propelled droplet motion. Scale bar: $50 \mu \mathrm{m}$. 


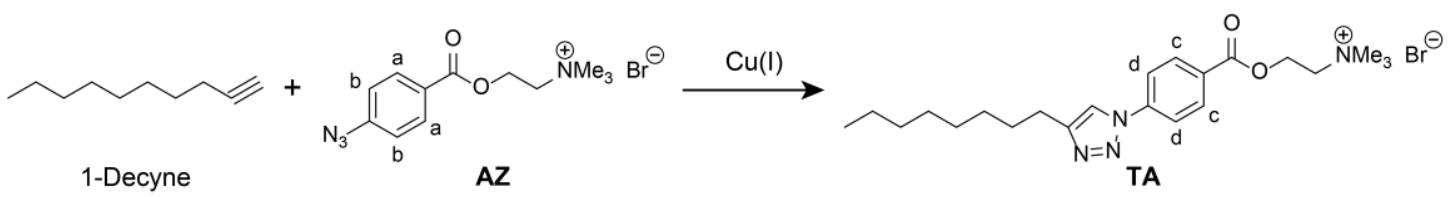

After $5 \mathrm{~min}$

AZ

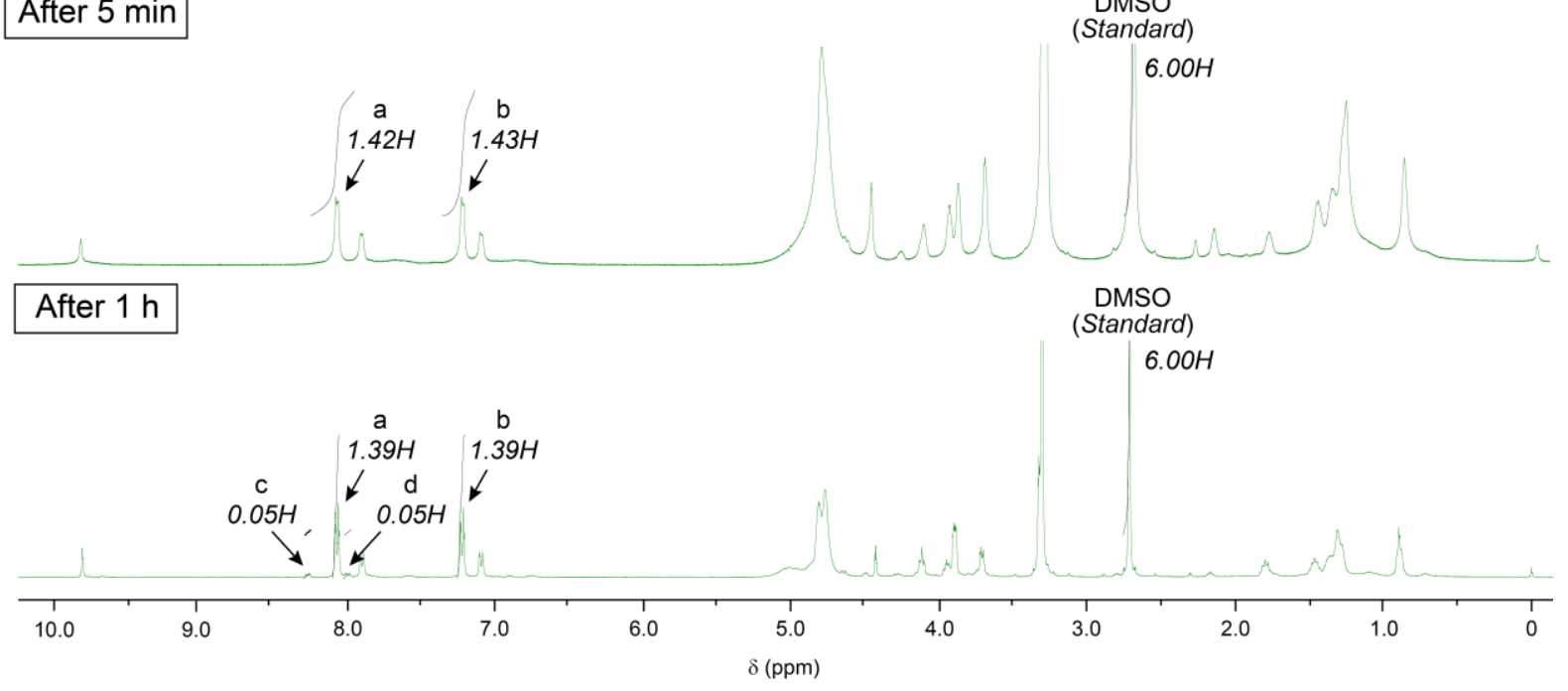

Figure S3. ${ }^{1} \mathrm{H}$ NMR spectra of the $\mathrm{D}_{2} \mathrm{O}$ and $\mathrm{CD}_{3} \mathrm{OD}$-mixed $1 / 2(\mathrm{v} / \mathrm{v})$ solution containing $\mathbf{H B A}(10 \mu \mathrm{L}), 1$ decyne $(1.79 \mu \mathrm{L}), \mathrm{CuSO}_{4} \cdot 5 \mathrm{H}_{2} \mathrm{O}(10 \mathrm{mM})$, sodium ascorbate $(50 \mathrm{mM}), \mathbf{A Z}(50 \mathrm{mM})$, and DMSO $(34.7 \mathrm{mM})$ used as a standard compound at room temperature $\left(23-25^{\circ} \mathrm{C}\right)$. A sample of the reaction mixture was examined 5 min and $1 \mathrm{~h}$ after sample preparation. The ratio was calculated by integration of the signals of benzene methine protons from $\mathbf{A Z}$ at $\delta 7.92$ and $7.11 \mathrm{ppm}$ and those from TA at $\delta 8.29 \mathrm{ppm}$ and $8.03 \mathrm{ppm}$, and the methyl proton of DMSO at $\delta 2.71 \mathrm{ppm}$ as an internal standard peak. 


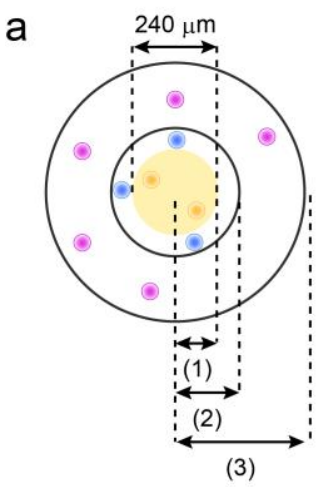

(1) Within $120 \mu \mathrm{m}$

(2) Within $150 \mu \mathrm{m}$

(3) $150 \mu \mathrm{m}$ or farther away
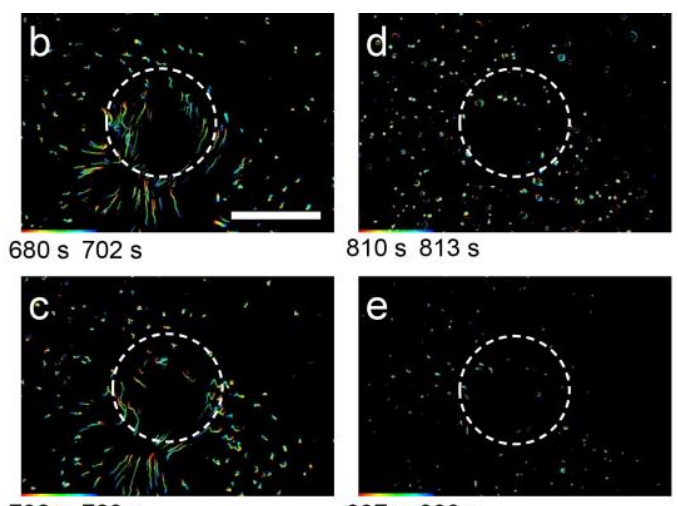

702 s $723 \mathrm{~s}$

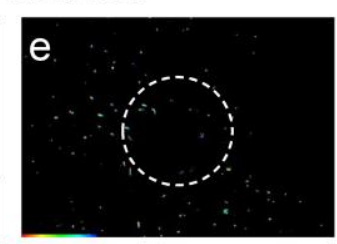

897 s 900 s
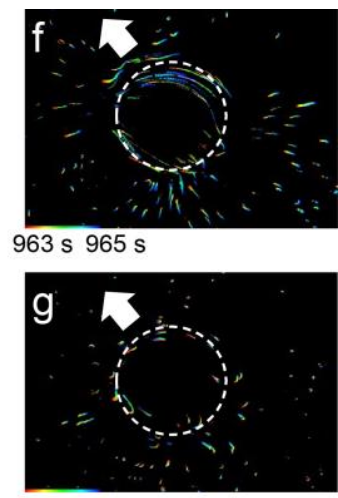

968 s 971 s

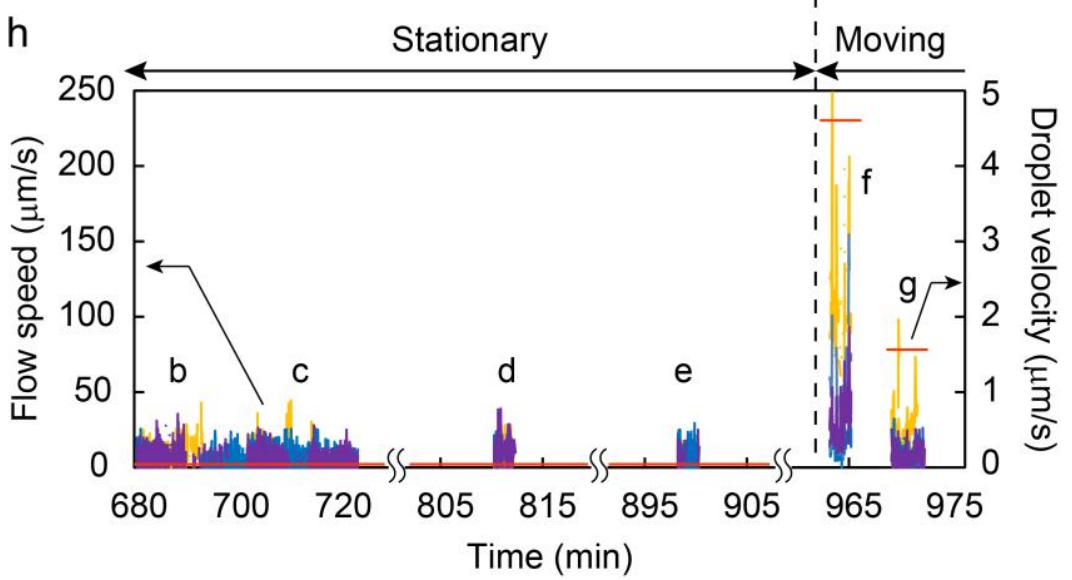

Figure S4. Flow analysis around the oil droplet with a diameter of $240 \mu \mathrm{m}$ before and after self-propelled motion using water-dispersed fluorescent microspheres (see Movie S5). (a) Schematic representation of the positions of analyzed fluorescent beads. The orange disk represents the droplet. (b-g) Trajectories of fluorescent microspheres in the area within $120 \mu \mathrm{m}$ of the droplet center, in the area in the range of 120-150 $\mu \mathrm{m}$ from the droplet center, and the area $150 \mu \mathrm{m}$ or farther away from the droplet center. Scale bar: $200 \mu \mathrm{m}$. (h) Time series of the flow speed of orange, blue, and purple fluorescent microspheres in $b-g$. The red line indicates the droplet velocity. 


\section{Table}

Table S1. Diameter and averaged motion speed for $200 \mathrm{~s}$ when the oil droplet started the motion.

\begin{tabular}{|c|c|c|}
\hline Entry & Diameter $(\mu \mathrm{m})$ & Motion speed $(\mu \mathrm{m} / \mathrm{s})$ \\
\hline 1 & 21 & 0.4 \\
\hline 2 & 25 & 1.2 \\
\hline 3 & 30 & 1.1 \\
\hline 4 & 37 & 0.9 \\
\hline 5 & 45 & 2.6 \\
\hline 6 & 56 & 7.2 \\
\hline 7 & 80 & 0.8 \\
\hline 8 & 120 & 0.4 \\
\hline 9 & 130 & 6.0 \\
\hline 10 & 173 & 5.7 \\
\hline 11 & 183 & 0.6 \\
\hline 12 & 200 & 1.4 \\
\hline 13 & 210 & 1.1 \\
\hline
\end{tabular}




\section{Description of video clips}

Five video clips have been attached to show the droplet dynamics in the emulsion, which was prepared in a solution containing $\mathrm{CuSO}_{4} \cdot 5 \mathrm{H}_{2} \mathrm{O}(10 \mathrm{mM})$, sodium ascorbate $(50 \mathrm{mM})$, and $\mathbf{A Z}(50 \mathrm{mM})$, and observed by phase contrast microscopy at room temperature $\left(23-25^{\circ} \mathrm{C}\right)$. The sequential dynamics, which consisted of the deformation of flocculate components into spherical droplets and the locomotion of droplets, were observed under conditions in which a 1,2,3-triazole-containing cationic surfactant, TA, was generated.

Movie S1: Start of self-propelled motion of oil droplets 10 min after starting observation. This movie was 100 times faster than the real time observations.

Movie S2: Aggregates formation at the rear of the self-propelled oil droplets in $20 \mathrm{mM}$ TA solution $2 \mathrm{~min}$ after the start of observation. This movie was the real time observations.

Movie S3: Visualization of the flow fields around an oil droplet with a diameter of $154 \mu \mathrm{m}$ before selfpropelling using water-dispersed fluorescent microspheres (diameter $=1 \mu \mathrm{m}$ ) 4 min after the start of observation. This movie was 5 times faster than the real time observations.

Movie S4: Visualization of the flow fields around an oil droplet with a diameter of $154 \mu \mathrm{m}$ after self-propelling using water-dispersed fluorescent microspheres (diameter $=1 \mu \mathrm{m}) 7 \mathrm{~min}$ after the start of observation. This movie was 5 times faster than the real time observations.

Movie S5: Visualization of the flow fields around an oil droplet with a diameter of $240 \mu \mathrm{m}$ before and after self-propelling using water-dispersed fluorescent microspheres (diameter $=1 \mu \mathrm{m}) 11$ min after the start of observation. This movie was 10 times faster than the real time observations. 